\title{
Bike handlebar grip in the rectum: minimally invasive endoscopic management
}

A 54-year-old man presented to the emergency department of our hospital complaining of severe pelvic pain from a large cylindrical-shaped object he had inserted into his rectum approximately 5 hours prior to presentation. The patient reported that multiple attempts to remove it at home had failed.

At clinical examination, there were no signs of peritonitis in the abdomen. Bowel sounds were decreased. An X-ray of the lower abdomen showed a cylindricalshaped object, $15 \mathrm{~cm}$ in length and $4 \mathrm{~cm}$ in diameter, extending from the upper sigmoid to the upper rectum. Remarkable intestinal deformity was observed, but there were no clear findings of perforation or ascites. The foreign body was not palpable in the rectum at digital exploration and, due to its shape, large size, and smooth surface, it was impossible to retrieve with simple maneuvering, including simultaneous application of suprapubic pressure.

Emergency lower gastrointestinal endoscopy revealed a bike handlebar grip, $15 \mathrm{~cm}$ in length, at the level of the rectosigmoid junction ( $\triangleright$ Fig. 1 a). Several attempts to remove the object using a polypectomy snare were unsuccessful because of the smooth margins, which did not allow grasping by the snare. A di- lation balloon was then inflated inside the hollow part of the foreign body and gently pulled out using rotation movements of the scope ( $\triangleright$ Fig. $\mathbf{1 b}, \mathbf{c}, \triangleright$ Video $\mathbf{1}$ ). No overt hemorrhage or perforation was observed. After removal of the bike handlebar grip, abdominal discomfort improved and no clinical adverse events were recorded.

Management of patients with rectal foreign bodies can be challenging. Such foreign bodies are often large and have physical characteristics that preclude manual or endoscopic retrieval, thus requiring surgery for their removal [1-5].

Endoscopy_UCTN_Code_TTT_1AQ_2AH

\section{Competing interests}

The authors declare that they have no conflict of interest.

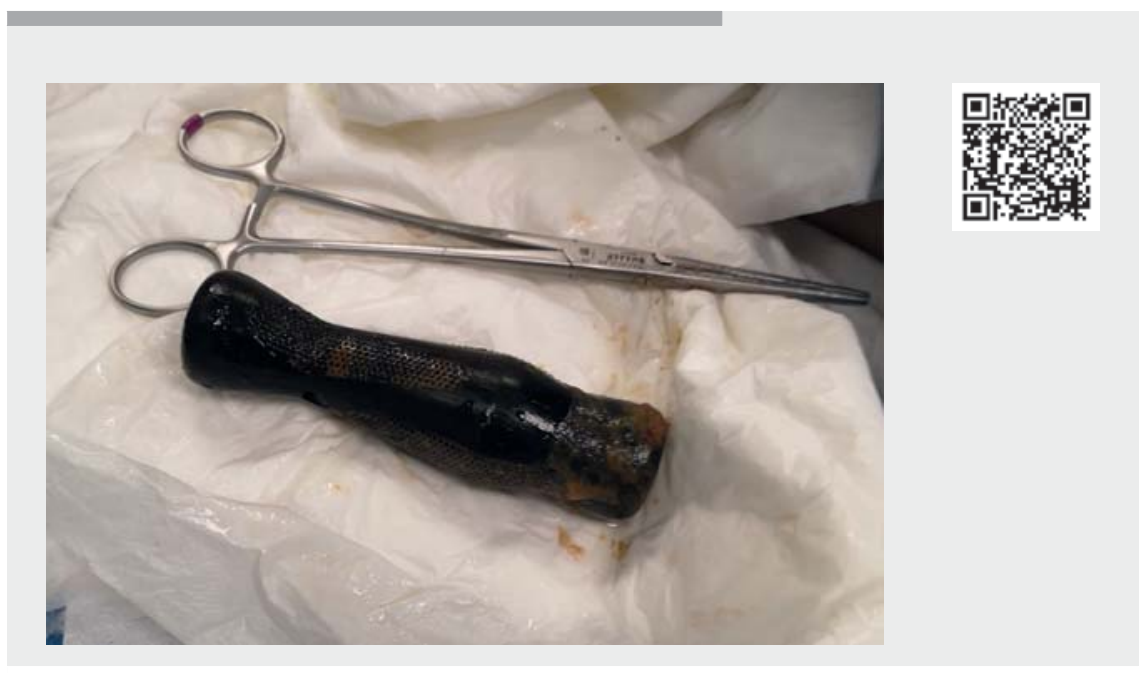

Video 1 Endoscopic removal of bike handlebar grip in the rectum.
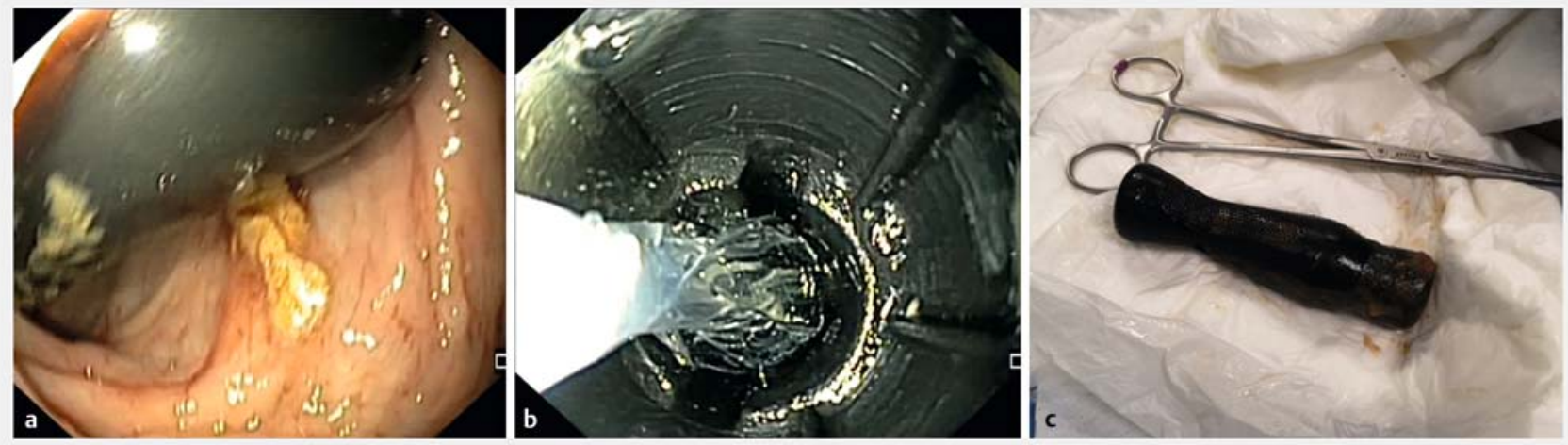

- Fig. 1 Endoscopic view of the rectal foreign body. a The rectal foreign body was located in the deep part of the proctosigmoid. $\mathbf{b}$ The rectal foreign body was removed slowly with a dilation balloon. $\mathbf{c}$ Removed rectal foreign body. 


\section{References}

Danilo Paduano ${ }^{1} \oplus_{\text {, Francesco Auriemma }}{ }^{1}$, Mario Bianchetti ${ }^{1}$, Alessandro Repici ${ }^{2,3}$, Benedetto Mangiavillano ${ }^{1,2}$

1 Gastrointestinal Endoscopy Unit, Humanitas Mater Domini, Castellanza, Italy

2 Department of Biomedical Sciences, Humanitas University, Rozzano, Milan, Italy

3 Endoscopy Unit, Humanitas Clinical and Research Center IRCCS, Rozzano, Milan, Italy

\section{Corresponding author}

Danilo Paduano, MD

Gastrointestinal Endoscopy Unit, Humanitas Mater Domini, Via Gerenzano 2, Castellanza 21053, Varese, Italy

danilo.paduano@libero.it
[1] Goldberg JE, Steele SR. Rectal foreign bodies. Surg Clin North Am 2010; 90: 173-184

[2] Cawich SO, Thomas DA, Mohammed F et al. A management algorithm for retained rectal foreign bodies. Am J Mens Health 2017; 11: 684-692

[3] Lin XD, Wu GY, Li SH et al. Removal of a large foreign body in the rectosigmoid colon by colonoscopy using gastrolith forceps. World J Clin Cases 2016; 4: 135-137

[4] Kim H, Choi S, Yun J. Colorectal foreign bodies: six cases report and review of the literature. J Trauma Inj 2015; 28: 51-54

[5] Yildiz SY, Kendirci M, Akbulut S et al. Colorectal emergencies associated with penetrating or retained foreign bodies. World J Emerg Surg 2013; 8: 25

Bibliography

Endoscopy 2022; 54: E42-E43

DOI 10.1055/a-1362-9026

ISSN 0013-726X

published online 5.3.2021

(C) 2021. Thieme. All rights reserved.

Georg Thieme Verlag KG, Rüdigerstraße 14,

70469 Stuttgart, Germany
ENDOSCOPY E-VIDEOS

https:/|eref.thieme.de/e-videos

口. Endoscopy E-Videos is an open access online section, 回: reporting on interesting cases and new techniques in gastroenterological endoscopy. All papers include a high quality video and all contributions are freely accessible online. Processing charges apply (currently EUR 375), discounts and wavers acc. to HINARI are available.

This section has its own submission website at

https://mc.manuscriptcentral.com/e-videos

\section{CORRECTION}

Bike handlebar grip in the rectum: minimally invasive endoscopic management

Paduano D, Auriemma F, Bianchetti M et al. Bike handlebar grip in the rectum: minimally invasive endoscopic management.

Endoscopy 2022; 54: E42-E43. doi:10.1055/a-1362-9026

In the above-mentioned article, the institution affiliations of A. Repici and B. Mangiavillano have been corrected. This was corrected in the online version on May 172022. 